\title{
Scientific Innovation's Two Valleys of Death: How Blood and Tissue Banks Can Help to Bridge the Gap
}

Sean D.A.Thompson*

\section{ABSTRACT}

Most biomedical basic research in the United States takes place at universities and research institutes and is funded by federal grants. Basic research is awarded billions of federal dollars every year, enabling new discoveries and greater understanding of the fundamental science that makes new innovations and therapies possible. However, when basic research yields an invention of practical use and the research evolves from basic to applied, the playing field changes. Pre-technology licensing federal dollars all but disappear, and innovations rely predominantly on private funding to support the full path from bench to bedside. It is along this path that the scientific advance faces two Valleys of Death. These sometimes insurmountable development stages are the product of the innovation's inherent financial, business and investment risks. Well-planned and executed in vivo studies using quality biological materials demonstrating proof-of-concept is often the key to bridging these gaps, and blood and tissue banks offer unique services and resources to enable this process.

Most biomedical basic research in the United States takes place at academic/medical universities and research institutes and is funded by federal grants. Basic research is awarded billions of federal dollars every year, enabling new discoveries and greater understanding of the fundamental science that makes new innovations and therapies possible [1]. However, when basic research yields an invention of practical use and the research evolves from basic to applied, ${ }^{1}$ the playing

Vice President of Business Development, Biobridge Global, San Antonio, Texas.

*(Correspondence: sean.thompson@biobridge global.org)

${ }^{1}$ As used in this article, "applied research" is defined as laboratory activities focused on discovery and development of clinically useful tools by researchers focused on exploiting the field changes. Pretechnology licensing federal dollars all but disappear, and inventions/innovations rely predominantly on private funding to support the full path from bench to bedside.

Biomedical and pharmaceutical development is quite risky, and the need to prove safety and efficacy through the FDA's NDA/PMA/BLA process is onerous and expensive. Additionally, everincreasing expenditures for $\mathrm{R} \& \mathrm{D}$ programs have produced diminishing returns [2]. Faced with this reality, large biomedical and pharmaceutical companies have decreased their internal product

basic science revelations they themselves have discovered, or known disease pathways about which these researchers have learned something new.

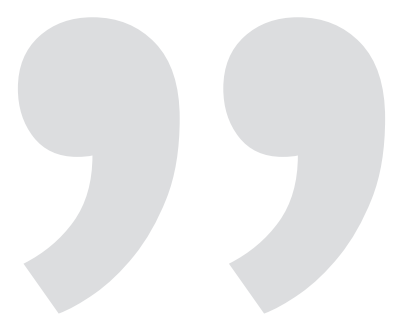

\section{Assuming that the fundamental science of the product is sound, most of the residual risk \\ of a therapeutic stems from execution.}

$R \& D$ expenditures and have sought to offload new product development risk onto capital markets by seeking more developed and proven - therefore, less risky-new-product candidates through licensing or development agreements with smaller investor-financed companies.

Similarly, these smaller investor-backed companies also seek more developed newproduct pipeline candidates, rather than early-development stage projects. New product or therapeutic candidates must be at least somewhat developed before even smaller investor-backed companies will consider licensing these assets from universities and institutes.

In this environment, established companies as well as startups demand increasingly sophisticated and compelling 
proof-of-concept data that products and therapies under consideration can survive the product and clinical development process through to marketing before they will consider entering into definitive licensing or codevelopment agreements.

\section{The reality of "bench to bedside"}

In the journey from scientific conceptualization to the actual application of a medical breakthrough, or from "bench to bedside," many scientific advances never make it off the bench. This is primarily because there are essentially no federal funds available to universities and institutes prior to licensing to support the discovery and development of tools physicians can prescribe to patients, which take advantage of the revelations of basic research. Arguably, the individuals best positioned to discover new therapeutics or diagnostics to exploit a newly discovered "drug" target or biomarker - and by doing so, to more fully validate the new discoveryare the researchers who made the discovery and identified its importance in the disease pathway. There are effectively no federal funds available for this purpose.

Scarce resources force many institutional researchers interested in developing therapeutics to seek less-than-ideal methods. For example, some seek to intervene in a newly discovered disease pathway by using known drugs, a practice called drug "repurposing" [3]. While this practice eliminates the immediate need for drug discovery, it also eliminates the possibility of attaining the "composition of matter"-type patent claims that drug and biotechnology companies strongly prefer over relatively weaker process-type patents. A strong defensible intellectual property position and the de facto monopoly position it enables are important to investorbacked companies as "insurance" that only their company will benefit from the substantial investment that must be made to commercialize a biomedical product.

Select institutions such as the California Institute for Regenerative Medicine, MIT's
Deshpande Center for Technological Innovation, and USC Stevens Center for Innovation do support applied research by providing the resources and value-added services critical to the process of commercial application of scientific advancements. However, such organizations are more the exception than the rule.

\section{The two valleys of death}

The relatively few scientific advances for which sufficiently novel tools are developed by researcher-inventors at institutions that do meet the basic criteria for out-licensing (e.g., drugs, biologics, clinical diagnostics, and medical devices) are soon confronted with the first of two "valleys of death" (Fig. 1). The first valley of death (Valley 1) refers to the time period between initial discovery of the invention and outlicensing. Many inventions that make it past the discovery hurdle in the development pathway ultimately "die" in Valley 1 for the same reason relatively few scientific advances make it off the lab bench-lack of resources. In this case, however, while the researcher had access to sufficient resources to generate a viable product candidate (and assuming an otherwise successful product), she/he lacked access to the skilled personnel, funds, facilities, and/or quality biomaterials necessary to perform critical preclinical in vivo investigative studies. Without reliable evidence from well-executed preclinical studies demonstrating positive proof of concept sufficient to provide potential licensees reasonable confidence that a similarly positive outcome can be expected in the clinic, there is little hope that the product will survive Valley 1.

The notion of the existence of a biomedical valley of death is far from new [4]. This phrase has generally been used to describe a time period in the life cycle of a company between in-licensing or organic development of a company's first product candidate and successful launch of the first revenue-producing product. It most frequently corresponds to the clinical trial period, and often is illustrated graphically as a V- or U-shaped chart meant to depict a period of steeply negative cash flows and a rapidly declining total cash position reflecting the huge costs of clinical trials. It is during this period that many companies run out of cash to support ongoing operations and "die" in bankruptcy or are sold at a loss. As used here, this classic valley of death is Valley 2. Valley 1 has the same root cause as Valley 2; it is a financial impediment. While much smaller in size, Valley 1 can be as deadly to clinical application of a bioscience breakthrough as can Valley 2.

Development of virtually all clinically useful biomedical tools requires financial

\section{FIG. 1. Valleys of death.}

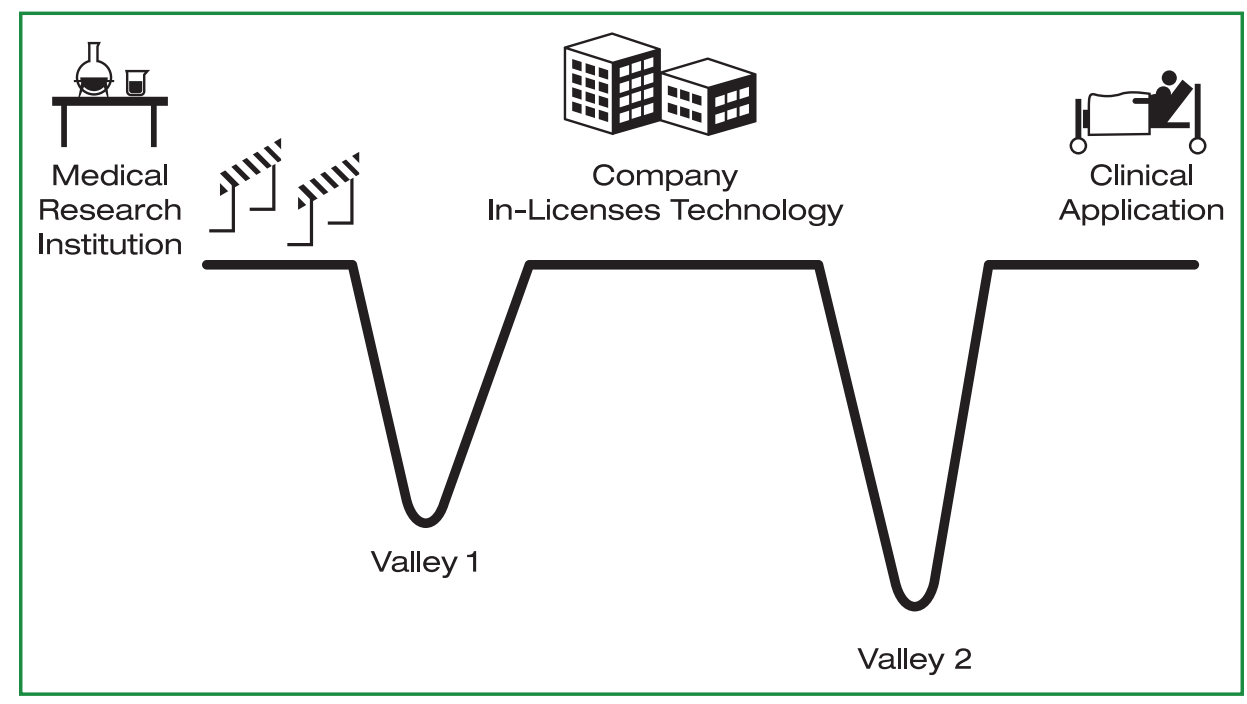


FIG. 2. Opportunity evaluation model.

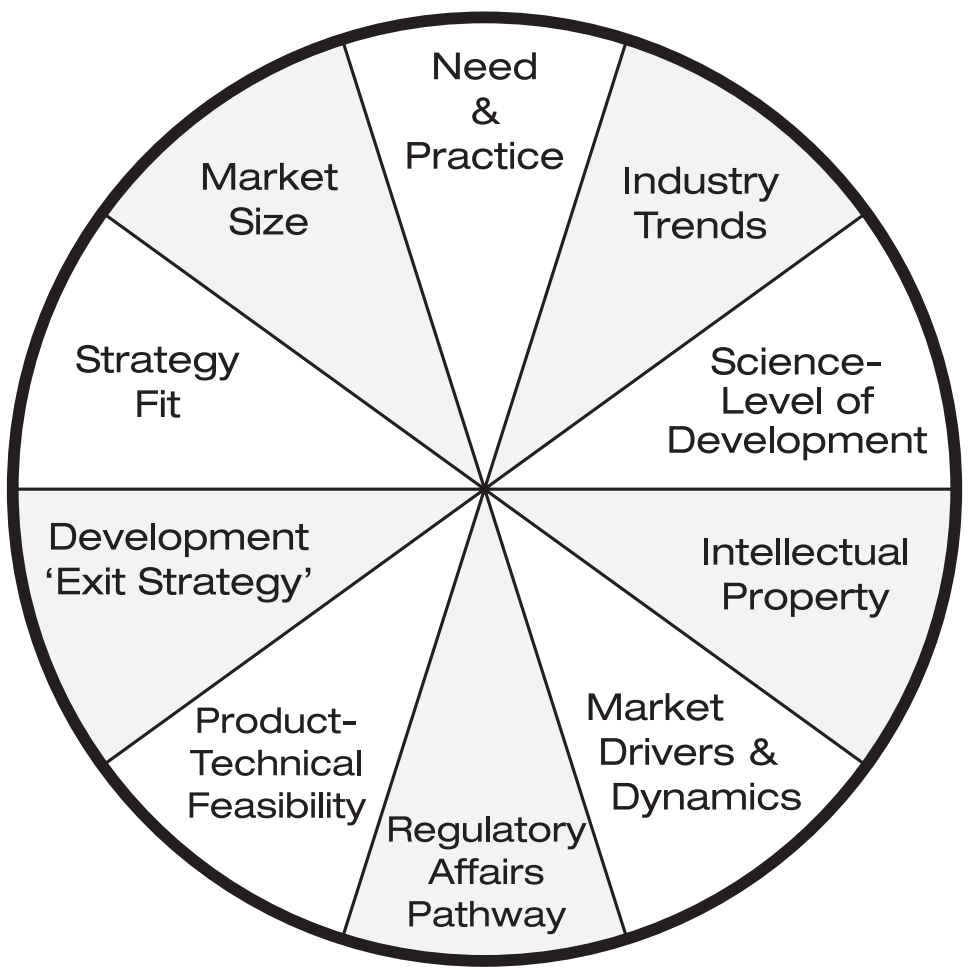

investment of some magnitude. While the U.S. Small Business Innovation Research/Small Business Technology Transfer [101] program provides important funding to support product-related applied/translational efforts focused on agency-defined areas of interest, the program is intended for small for-profit businesses (e.g., the primary investigator must be employed by the small business). While some of the funds may be used at institutions (as subcontractors), the applicant must be a small business, not an institution and generally not prior to institutional technology transfer outlicensing. Thus, most funding for discovery and development of novel biomedical tools comes from private investment and/or is driven by privatesector companies.

Holders of private investment funds, whether for-profit concerns or not-forprofit organizations, expect to receive some level of positive return on investment. Since biomedical investments are generally quite risky, it is not surprising that managers of these funds typically require a substantial expected return to compensate for the financial risks taken. It is this notion of financial/business/investment risk that is the root cause of the two valleys of death (Fig. 2).

\section{Expected value and risk}

Since the expected value of any financial investment is equal to the realizable market size multiplied by the probability of success of achieving financial return, the drivers of investment decision-making are (1) achievable market size given the planned investment and (2) risks inherent to the endeavor. Accordingly, biomedical investors are most interested in (1) companies with pipeline products with a total realizable market potential of sufficient size, and (2) companies that have benefitted from solid development decisions along the way, and thus have

Realizable Market Size $\times$ Probability of Success of ROI = Expected Value of Investment been "de-risked" sufficiently for investors to conclude probability of success is reasonable.

For any given product opportunity, the realizable market size "is what it is." While differing levels of marketing expenditure can affect speed and depth of market penetration, by the time a biomedical product approaches the development phase implied by Valley 1, the product characteristics responsible for determining realizable market size (the disease addressed, whether it is a drug, cell therapy, therapeutic protein, etc.) are "hard-wired" into the product and are largely unchangeable. It is quite difficult, if not impossible, to pivot such a biomedical product in response to market feedback or to bring the product back in line with the desired target product profile.

In contrast, the second determinant of a given product's expected value, the riskiness of the endeavor, has components that are more amenable to change after creation of the product. Assuming that the fundamental science of the product is sound, most of the residual risk of a therapeutic stems from execution risk. "Execution risk" is the decision-making of the therapeutic's inventor and the company's management team responsible for product development. In other words, the decisions made pursuant to putting the scientific advance into the form of a therapeutic - the clinical tool physicians will prescribe to their patients, thus the vehicle used to translate the scientific advance into a medical breakthroughare the largest source of non-productrelated investment risk in any biomedical business opportunity.

\section{Bridging the valleys of death: the role of blood and tissue banks}

Blood and tissue banks can help in the translation of biomedical advances into clinically useful tools and their delivery to the bedside. Independent, nonprofit blood 
and tissue banks have the freedom, charters, and mission to engage in activities that are out of scope for most universities and not financially attractive enough for most private for-profit companies to undertake.

Blood and tissue banks have access to human biomaterials and related skills that researchers and biomedical companies can leverage to attenuate the perceived risk of their pipeline biomedical products. Also, many are members of blood and tissue bank alliance networks, which contract with biomedical companies for services on behalf of their members.

For example, with regard to Valley 1, researchers can reduce perceived risk of novel cell- and tissue-based technologies by sourcing the human biomaterials used in their research from accredited blood and tissue banks. Because accredited blood and tissue banks follow strict standard operating procedures and comply with all relevant accrediting agency and regulatory agency requirements, researchers can be confident that the human biomaterials used to conduct research are of the highest quality. Some blood and tissue banks also have considerable experience with cell processing, component separation, cell banking, biomarker-based cell quantification, custom antigen assays, and other core competencies.

Some blood and tissue banks have active applied research laboratories and are especially receptive to partnering with researchers with technologies showing promise to address long-standing areas of need within the industry. Some blood and tissue banks, especially ones that are a part of a parent organization with several divisions encompassing different but complementary capabilities, offer advanced services, possess significant biomedical processing facilities, have broad core competencies and can be especially helpful at bridging the valleys of death. As technologies enabling costeffective manufacturing of cell-based therapeutics, rapid and reliable methods for predicting cell potency, and closedsystem fill and finish become available, researchers can partner with more advanced blood and tissue banks for IND-enabling cell-based therapeutic products as early as the preclinical phase (Table 1).

Biotechnology and cell-based therapeutics companies approaching Valley 2 also can benefit from blood and tissue banks' increased capabilities. While advanced cell-based therapeutics such as Dendreon's Provenge are relatively new, blood and tissue banks have been operating under cGMP and/or GTP controls for decades. Blood and tissue banks are accustomed to operating under the strictest qualitycontrol standards because red blood cells, plasma, platelets, cord blood, and implantable tissues must be safe and effective every time. Donated and processed human cell and tissue products are biotherapeutics because the cell-based products of blood and tissue banks (red cells, whole blood, platelets, cord blood, and peripheral blood stem cells) confer therapeutic benefit via the use of living cells.

Blood and tissue banks wishing to engage in interstate distribution of their blood products must seek licensure of their products through the FDA's biologics

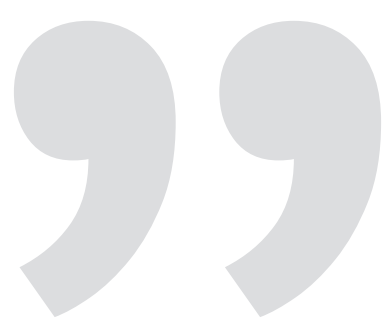

For investors, companies with cell-based therapies in their pipelines may greatly diminish perceived risk by partnering with blood and tissue banks. license application (BLA) process. Licensure of cord blood bank products is not mandated by the FDA, but industry best practice for cord blood banks is to seek BLA licensure. Many blood and tissue banks (especially the more innovative organizations) maintain a close relationship with the FDA's Center for Biologics Evaluation and Research to ensure compliance with FDA guidelines.

For investors, companies with cell-based therapies in their pipelines may greatly diminish perceived risk by partnering with blood and tissue banks, and especially advanced blood and tissue banks for the recovery, safety testing, processing, manufacturing, quality assurance, distribution, and perhaps eventually administration of cell-based therapies.

\section{Profile of an advanced blood and tissue bank: BioBridge Global}

Headquartered in San Antonio, Texas, BioBridge Global is the 501(c)(3) not-forprofit parent organization to three operating subsidiaries and one supporting foundation structured similarly as not-forprofit organizations. From its beginning in 1974 as South Texas Regional Blood Bank to the establishment in 2007 of our blood and tissue safety testing group QualTex Laboratories to the 2010 founding of our regenerative medicinefocused group known as GenCure, the organization that has grown into BioBridge Global has a history of missiondriven innovation.

"Connecting donors with patients, needs with solutions, and opportunities with growth" is BioBridge Global's mission. BioBridge seeks to save and enhance lives around the world by building relationships with like-minded nonprofit and for-profit organizations and by leveraging the complementary resources and capabilities of the three operating subsidiaries, as well 


\section{Table 1.}

\section{Services offered by most blood centers}

\section{Biologic collection/sourcing}

Expired red blood cells and whole blood-derived platelet products

Plasma, recovered or salvaged

Platelet collections (apheresis)

Pooled cryoprecipitate

Select cell processing

Infectious disease testing

Distribution

Product quality control testing

Capabilities/services offered by advanced blood and tissue centers

\section{Biologic collection/sourcing}

Customized cell/component collections

Cord blood and birth tissues

Biobanking

Cell fractions

Mobilized PBSC collections

Plasma or serum, disease-state collections

Cadaveric tissues (orthopedic, skin, select organs, veins, heart valves)

Testing: HLA, NAT, infectious disease

Infusions (limited)

Storage and logistics

Facilities leasing-colocation of startups on blood and tissue center properties

\section{Applied/translational research}

Assisting with development of novel technologies

Centralized IRB

Regulatory affairs services

Future potential advanced blood and tissue center offerings

Biotechnology company partnering to enable clinical translation of novel technologies

Pharmacy-storage, logistics, and point-of-care processing

cGMP-compliant custom/contract cell expansion services

\section{Cellular therapy-relevant assays (pending standardization and availability)}

Cell-based therapy quality assurance/batch release assays

In-process monitoring of expanded/processed cells

Optimization of biosourced cells

Novel cell characterization

Health care delivery as the economies of scale and scope of the organization as a whole.

BioBridge's latest commitment to missiondriven innovation is embodied by our GenCure subsidiary. Comprising the GenCure Tissue Center, the GenCure Cord Blood Center (with the Texas Cord Blood Bank), and the GenCure Cellular Therapy Center, GenCure's goal is to help enable and realize the potential of regenerative medicine and cell-based therapeutics. GenCure does this by providing health care-related services and products and supporting the efforts of researchers and biomedical companies to effect cures for the world's most intractable diseases.

\section{Author Disclosure Statement}

No competing financial interests exist.

\section{REFERENCES}

\section{Primary Literature}

1. Francis FS. (2013). Executive Summary Budget Mechanism. National Institutes of Health FY 2013 Congressional Justification: ES-31.

2. Butler D. (2008). Translational research: crossing the valley of death. Nature 453:840-842.

3. Francis FS. (2013). Executive Summary Budget Mechanism. National Institutes of Health FY 2013 Congressional Justification: ES-16.

4. Steinmetz KL and EG Spack. (2009). The basics of preclinical drug development for neurodegenerative disease indications. BMC Neurol 9(Suppl 1):S2.

\section{Website}

101. Zyn Systems. Small Business Innovation Research (SBIR)/Small Business Technology Transfer (STTR) [Internet.] Sequim, Wash.: SBIR Gateway . 2014. www.zyn.com/sbir/ 